Article

\title{
An Experimental Study on the Macroscopic Spray Characteristics of Biodiesel and Diesel in a Constant Volume Chamber
}

\author{
Hongzhan Xie, Lanbo Song, Yizhi Xie, Dong Pi, Chunyu Shao and Qizhao Lin * \\ Department of Thermal Science and Energy Engineering, University of Science and Technology of China, \\ Hefei 230027, China; E-Mails: hanhan16@mail.ustc.edu.cn (H.X.); lbsong@mail.ustc.edu.cn (L.S.); \\ xyzlz1@mail.ustc.edu.cn (Y.X.); pidong91@mail.ustc.edu.cn (D.P.); scy19@mail.ustc.edu.cn (C.S.) \\ * Author to whom correspondence should be addressed; E-Mail: qlin@ustc.edu.cn; \\ Tel.: +86-551-6360-0430; Fax: +86-551-6360-3487.
}

Academic Editor: Chang Sik Lee

Received: 25 March 2015 / Accepted: 11 June 2015 / Published: 17 June 2015

\begin{abstract}
The objective of this study was to investigate the macroscopic spray characteristics of different $0 \%-100 \%$ blends of biodiesel derived from drainage oil and diesel (BD0, BD20, BD50, BD80, BD100), such as spray tip penetration, average tip velocity at penetration, spray angle, average spray angle, spray evolution process, spray area and spray volume under different injection pressures $(60,70,80,90,100 \mathrm{MPa})$ and ambient pressures $(0.1,0.3,0.5,0.7,0.9 \mathrm{MPa})$ using a common rail system equipped with a constant volume chamber. The characteristic data was extracted from spray images grabbed by a high speed visualization system. The results showed that the ambient pressure and injection pressure had significant effects on the spray characteristics. As the ambient pressure increased, the spray angle increased, while the spray tip penetration and the peak of average tip velocity decreased. As the injection pressure increased, the spray tip penetration, spray angle, spray area and spray volume increased. The increasing blend ratio of biodiesel brought about a shorter spray tip penetration and a smaller spray angle compared with those of diesel. This is due to the comparatively higher viscosity and surface tension of biodiesel, which enhanced the friction effect between fuel and the injector nozzle surface and inhibited the breakup of the liquid jet.
\end{abstract}

Keywords: biodiesel; diesel; macroscopic spray characteristics; visualization 


\section{Introduction}

Traditional fossil fuels are non-renewable and expected to eventually be exhausted in a few decades. In addition, burning fossil fuels generates a large amount of pollutants exacerbating environmental degradation [1]. Therefore, finding economically viable and sustainable alternative fuels has become an essential issue. Among the various alternative fuels, biodiesel is the most popular [2]. Both the academic and industrial worlds have paid great attention to biodiesel fuels - produced from animal fats, vegetable oils and discarded biological oil (drainage oil) [3] — because is a clean and renewable fuel with reduced soot and nitrogen oxides $\left(\mathrm{NO}_{x}\right)$ emissions by virtue of its high oxygen content [4]. However, in comparison to conventional diesel biodiesel is hardly atomized because of its intrinsic higher surface tension and viscosity. To improve these properties, biodiesel is currently blended with diesel. Moreover, biodiesel fuel blends offer significantly higher lubricity [5] and can be used without modification of the engine [6]. The quality of the fuel-air mixture, which in turn determines the combustion process and emission characteristics, depends on the spray characteristics of the biodiesel-diesel blend [7,8]. Due to their different microstructure and physical properties biodiesel differs from conventional diesel fuel in some key characteristics such as spray tip penetration, spray cone angle and spray area. There have been many investigations into the spray characteristics of biodiesel and its blends with diesel.

It was suggested by most researchers that the physical properties of liquid fuel were the intrinsic factors affecting its spray characteristics [9-13]. Boggavarapu et al. [9] reviewed the effect of fuel properties on the atomization process for both biofuels and fossil fuels and summarized that biodiesel sprays showed faster penetration and narrower spray plume angles and larger droplet sizes as compared to diesel. Battistoni et al. [10] investigated spray simulation results, indicating that among the properties affecting the spray characteristics, density and viscosity played the most important roles. Diesel fuel provided a significantly higher penetration and lower cone-angle compared with biodiesel in a convergent conical nozzle. Wang et al. [11] compared the spray characteristics of biodiesel and diesel under ultra-high injection pressure conditions. They found that biodiesel presented longer spray tip penetration, smaller spray angle, projected area and volume than diesel spray, but larger Sauter mean diameter (SMD) due to its higher viscosity and surface tension. Yoon et al. [12] and Yuan et al. [13] reported that the temperature had a great influence on the physical properties of biodiesel. Compared to the fuel properties, the control parameters such as injection pressure, ambient pressure and blending ratio had more significant influence on the spray behavior in practice. Pan et al. [14] presented an experimental study on the spray and combustion process of diesel engines fueled by biodiesel. They found that with the increase of injection pressure both the spray cone angel and the spray penetration of biodiesel increased, and the spray atomization improved. A similar study was conducted by Agarwal et al. [15]. They observed a longer spray tip penetration and larger spray area with an increase in fuel injection pressure in a biodiesel fuelled common rail direct injection diesel engine. Delacourt et al. [16] studied the effect of injection pressure reaching $250 \mathrm{MPa}$ on the macroscopic spray characteristics for a high pressure range using optical techniques. They found that an increase in injection pressure resulted in increased spray-tip penetration. However, the diesel spray angle remained nearly constant regardless of the injection pressure increase. The effect of ambient pressure on the macroscopic spray characteristics was investigated by Agarwal et al. [17]. The results showed 
that with an increase in ambient pressure, spray tip penetration decreased, while cone angle and spray area increased. The spray tip penetration, cone angle and spray area increased with the increase in mixing ratio of biodiesels because of fuel density differences. Kim et al. [18] also suggested that the ambient pressure had a significant effect on the spray characteristics of biodiesel and dimethyl ether (DME) under various experimental conditions and found that the spray tip penetration and spray area decreased as the ambient pressure increased. To compare the different spray characteristics of diesel and biodiesel, Chen et al. [19] conducted atomization experiments with diesel and biodiesel, resulting in longer spray tip penetration and larger droplets for biodiesel compared with diesel, which were believed to be caused by the relatively higher viscosity and surface tension of biodiesel. Mohan et al. [20] investigated the spray characteristics of biodiesel and its blends compared with diesel fuel. Biodiesel showed higher spray tip penetration and velocity, but narrower spray angles, and the ambient pressure had a more significant effect on spray angle while injection pressure showed no contribution. Lee et al. [21] investigated the effect of the biodiesel mixing ratio on the atomization and combustion characteristics using a common-rail engine system, and found that due to the higher viscosity and surface tension of the biodiesel than conventional diesel fuel, the mean size of the droplets increased as the ratio of biodiesel in the blends became higher. However, spray tip penetration was little influenced by the biodiesel mixing ratio. Gao et al. [22] compared experimental and simulated spray characteristics results, including the macroscopic and microscopic spray properties of three different biodiesels and blends. The authors concluded that with increasing concentration of biodiesel in the fuel, spray penetration and spray speed increased, while the spray cone angle decreased. Simulation results presented similar macroscopic spray characteristics as the experimental results for biodiesel. The blend fuels showed a larger SMD than diesel due to the higher viscosity and surface tension of the biodiesel. An investigation of the spray characteristics of biodiesel and diesel in a high pressure chamber (an effective device to simulate the engine environment) was performed by Srichai et al. [23]. The results showed that the spray tip penetration of biodiesel was longer than that of diesel. It also suggested that the effect on the spray mixture formation was stronger with increasing the density and viscosity of biodiesel. Desantes et al. [24] established a model predicting the spray axis velocity and spray tip penetration with a series of assumptions. It was based on momentum flux conservation along the axis, and the model was validated by experimental results.

Many studies have been conducted to evaluate the effects of a single or two factors such as injection pressure or ambient pressure on the spray characteristics of biodiesel and diesel, while a systematic investigation of the spray characteristics of different mixing ratios of biodiesel and diesel under various injection pressures and ambient pressure are not fully clarified. Therefore, the aim of this work was to investigate the macroscopic spray characteristics of biodiesel and its blends with diesel under various injection pressures and ambient pressure conditions. The characteristics like spray tip penetration, average tip velocity at penetration, spray angle, average spray angle, spray evolution process, spray area and spray volume were used to understand the spray characteristics of biodiesel and its blends, which may provide some guidance and advice for practical applications of biodiesel-diesel blended fuels. The spray characteristics were measured using a spray visualization system in a common rail system equipped with a constant volume chamber. 


\section{Experimental Apparatus and Procedures}

\subsection{Experimental Apparatus and Methods}

All experiments were conducted at room temperature. The experimental setup for investigating the biodiesel-diesel blends spray is shown in Figure 1a,c. The experimental equipment consisted of a high-speed photography system and a high pressure injection system. The high-speed photography system was composed of a high speed camera, data acquisition-processing and continuous laser light source. The high speed camera was used to record the spray images $(896 \times 848$ pixel). The imaging speed was set to $10,000 \mathrm{fps}$ (frame per second) with exposure time of 1/20,000 s. The high pressure injection system consisted of an air compressor, common rail system, fuel injector, single-hole injection nozzle, constant volume chamber and ambient-pressure source. The common rail system supplied the highly pressurized fuel. The injector injected the fuel in the constant volume spray chamber $(350 \mathrm{~mm} \times 350 \mathrm{~mm})$, which was made of stainless steel and designed to withstand pressures up to $4 \mathrm{MPa}$, as shown in Figure 1d. A safety valve, pressure gauge and fuel injector were installed on the top of the chamber. There were four optical round windows $(10 \mathrm{~mm} \times 110 \mathrm{~mm})$ bolted onto the constant volume spray chamber with the help of flanges, which were used for optical measurements and capturing the images under various experimental conditions. The ambient pressure in the chamber was provided using nitrogen gas. As shown in Figure 1e, the test injector had a $0.3 \mathrm{~mm}$ nozzle diameter at $700 \mu$ s pulse injection duration and was operated by an injector energizer. The laser light was placed perpendicularly to the high speed camera. The polarized light was obtained from the laser light beam by using a polarizer, and went through the axis of the nozzle. During the spray experiments, the polarized light passed through the cone spray, and the lightened area was the scope of photos taken by the high speed camera. The spray time started with the first visible spray picture, and ended with the last visible spray picture before separating the injector hole. All images of one complete injection event were captured by the high speed camera in three seconds. Certain images presenting the spray process were from all the recorded images and were processed in the computer with an image analysis program to obtain the spray characteristic data.

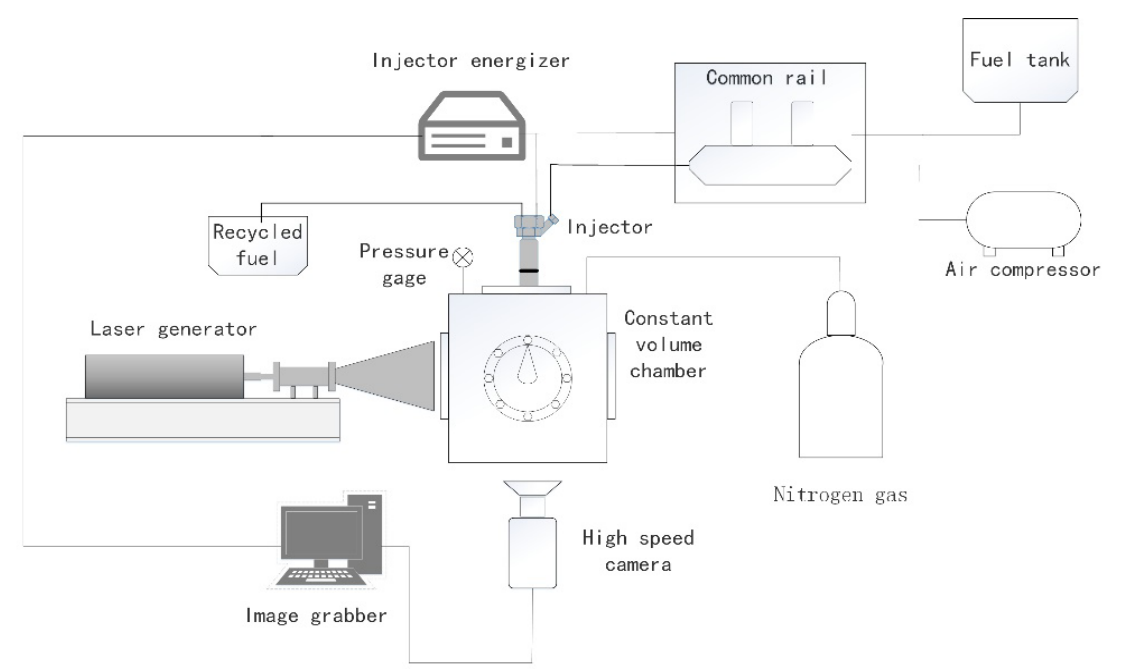

(a)

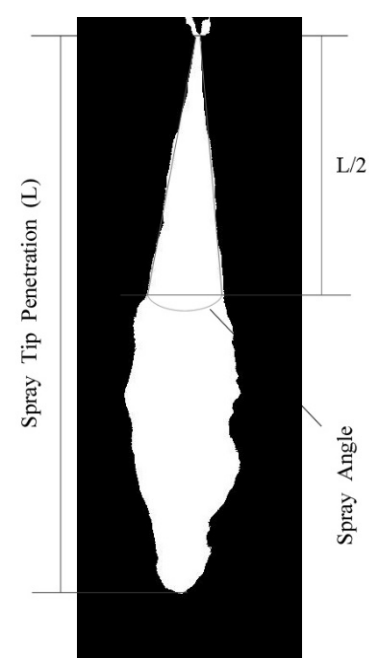

(b)

Figure 1. Cont. 


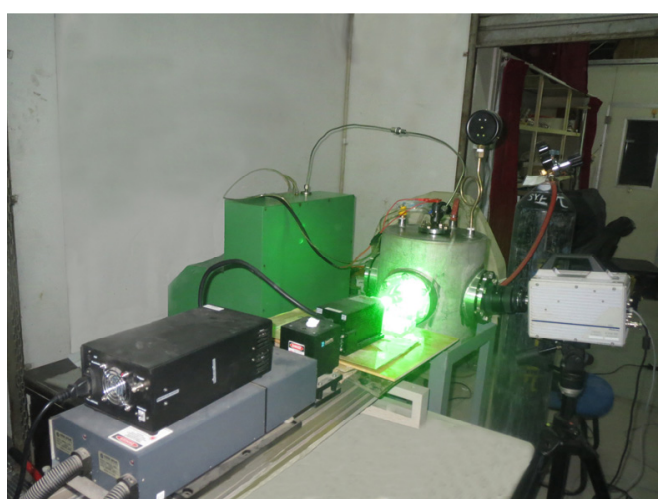

(c)

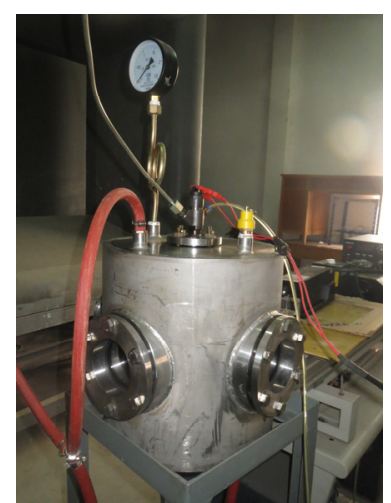

(d)

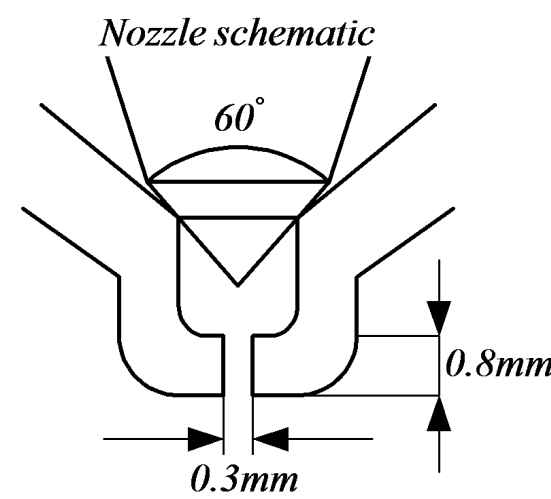

(e)

Figure 1. (a) schematic of the spray visualization system; (b) the definitions of spray tip penetration and spray angle; (c) setup of the high speed imaging system; (d) the constant volume chamber; (e) schematic of the mini-sac nozzle.

\subsection{Fuels and Working Conditions}

In order to investigate the spray behavior of the biodiesel-diesel blends used in the experiment, biodiesel derived from drainage oil, diesel and biodiesel-diesel blends were used as test fuels. The selected blend ratios were BD0, BD20, BD50, BD80 and BD100 on a volume basis of biodiesel in a biodiesel-diesel fuel mixture. They correspond to $0 \%$ biodiesel-100\% diesel fuel (BD0), $20 \%$ biodiesel-80\% diesel fuel (B20), 50\% biodiesel-50\% diesel fuel (B50), 80\% biodiesel-20\% diesel fuel (B80), and 100\% biodiesel-0\% diesel fuel (B100), respectively. Predetermined volumes of the fuels were homogenized by a magnetic stirrer for ten minutes. Then, the final blends were kept in a graduated glass vial for observing the solubility and the physical stability. None of the blends showed any precipitation or stratification. The main properties of the biodiesel and diesel are listed in Table 1. Injection pressures were changed from 60 to $100 \mathrm{MPa}$ in $10 \mathrm{MPa}$ steps. Ambient pressures of 0.1, 0.3, 0.5, 0.7 and 0.9 MPa were employed. Table 2 lists the working conditions used in the present study. The fuel injection quantities for each injection pressure under the ambient pressure $0.1 \mathrm{MPa}$ were measured, and the data is listed in Table 3.

Table 1. Properties of test fuels.

\begin{tabular}{ccc}
\hline Properties & Diesel & Biodiesel \\
\hline Density $(\mathrm{g} / \mathrm{mL})\left(40^{\circ} \mathrm{C}\right)$ & 0.85 & 0.88 \\
Kinetic viscosity $\left(\mathrm{mm}^{2} / \mathrm{s}\right)\left(40^{\circ} \mathrm{C}\right)$ & 2.46 & 4.19 \\
Surface tension $(\mathrm{mN} / \mathrm{m})$ & 29.5 & 32.4 \\
Cold filter plugging point $\left({ }^{\circ} \mathrm{C}\right)$ & 4 & 10 \\
Flash point temperature $\left({ }^{\circ} \mathrm{C}\right)$ & 75 & 165.0 \\
Cetane number $(\mathrm{CN})$ & 47.7 & 49 \\
\hline
\end{tabular}


Table 2. The working conditions of the experiment.

\begin{tabular}{cc}
\hline Injection System & Common Rail Fuel Injection System \\
\hline Fuel & Diesel, biodiesel, biodiesel-diesel blends (BD20, BD50, BD80) \\
Nozzle type & Mini-sac nozzle \\
Hole number & Single hole \\
Diameter of nozzle hole & $0.3 \mathrm{~mm}$ \\
Injection pressure & $60,70,80,90,100 \mathrm{MPa}$ \\
Pulse injection duration & $700 \mu \mathrm{s}$ \\
Ambient temperature & $293 \mathrm{~K}$ \\
Ambient pressure & $0.1,0.3,0.5,0.7,0.9 \mathrm{MPa}$ \\
\hline
\end{tabular}

Table 3. The fuel injection quantities for each injection pressure.

\begin{tabular}{cccccc}
\hline Injection Pressure & \multicolumn{5}{c}{ Fuel Injection Quantities (mg/Injection) } \\
\cline { 2 - 6 } (MPa) & BD0 & BD20 & BD50 & BD80 & BD100 \\
\hline 60 & 17.06 & 16.78 & 16.615 & 16.45 & 16.23 \\
70 & 42.51 & 41.94 & 41.54 & 41.13 & 40.58 \\
80 & 68.04 & 67.11 & 66.46 & 65.81 & 64.93 \\
90 & 93.54 & 92.28 & 91.38 & 90.49 & 89.29 \\
100 & 119.03 & 117.44 & 116.30 & 115.16 & 113.64 \\
\hline
\end{tabular}

\section{Results and Discussion}

\subsection{Spray Tip Penetration}

Spray tip penetration was defined as the distance between the nozzle tip and the farthest axial location of the spray boundary, as shown in Figure 2. A certain threshold value of light intensity was selected to demarcate the spray boundary, thus the spray tip penetration and spray angle could be measured. Spray tip penetrations for biodiesel and diesel are illustrated in Figure $2 \mathrm{a}-\mathrm{j}$, where Figure $2 \mathrm{a}-\mathrm{e}$ were at a blend ratio of BD80, Figure $2 \mathrm{f}-\mathrm{j}$ were under a certain injection pressure of $80 \mathrm{MPa}$. As time elapsed, all the tip penetrations increased after being injected by the injector, with a trend of rapid growth during the early injection stage followed by a gradual smoothing process later on. The evolution of the spray tip penetration was similar to the trend predicted by the equation of Delacourt et al. [16]. The uncertainty quantification is presented in the curves in Figure 2a-e. To obtain the data of the uncertainty quantification, the penetration of BD80 was measured three times for each similar condition. The results showed that the dispersion from the mean value for all the repeated experiments was within $5 \%$.

Higher injection pressures contribute to an increase in penetration, leading to a longer tip penetration for the same elapsed time. There were significant differences between the penetration values under different injection pressures. For a given ratio of fuel under all the ambient pressures, the spray tip penetration for an injection pressure of $100 \mathrm{MPa}$ was the longest, which might be due to the higher momentum produced by a high discharge coefficient from the nozzle exit, and the shortest was for $60 \mathrm{MPa}$. Under ambient pressure of $0.1 \mathrm{MPa}$, the approximate longest spray tip penetration at $1.5 \mathrm{~ms}$ after injection was $160 \mathrm{~mm}$ and the largest gap was about $40 \mathrm{~mm}$, and values of $120 \mathrm{~mm}$ and $20 \mathrm{~mm}$, respectively, occurred under an ambient pressure of 0.9 $\mathrm{MPa}$. As the ambient pressure increased, 
the spray tip penetration decreased significantly, and the difference between penetration under different injection pressures was reduced slightly. The air density in the constant volume chamber increased with the raising ambient pressure, resulting in higher shear resistance to the droplet velocity near the tip of the spray, which led to the reduction of spray tip penetration. At a certain injection pressure, the spray tip penetration showed a similar pattern as the blend ratio increased. However, there was a slight trend under ambient pressure of $0.1 \mathrm{MPa}$ and $0.3 \mathrm{MPa}$, whereby BD100 showed a shorter tip penetration compared with other fuels, while BD20 showed a longer one. The shorter penetration of BD100 may be because of the decreasing velocity of biodiesel exiting the nozzle compared with the other fuels resulting from the increasing friction effect between the fuel and the injector nozzle surface, caused by the relatively higher viscosity and surface tension of biodiesel. The longer tip penetration of BD20 may be attributed to the better lubricity at an appropriate blend ratio. Despite the inconspicuous differences in spray tip penetration at different blend ratios, they were similar for BD0 and BD20 under all conditions.

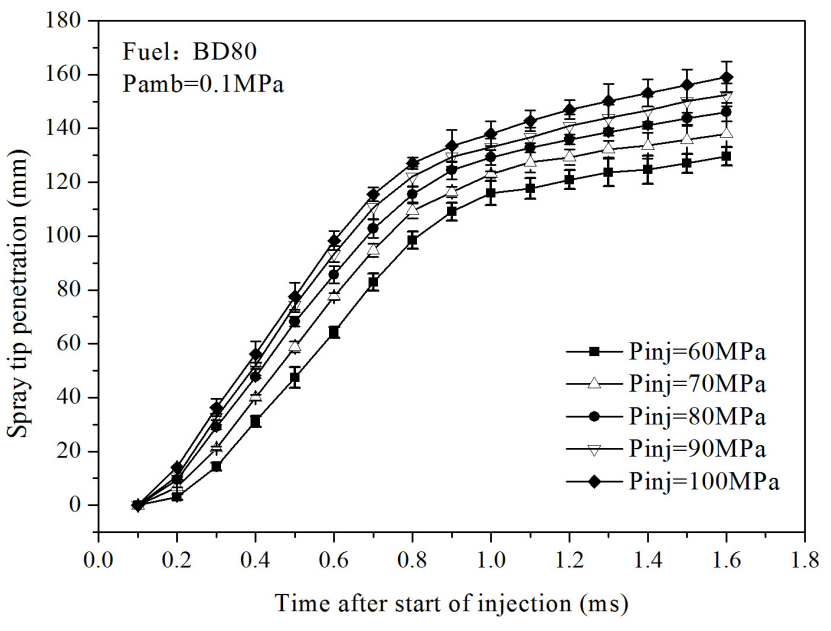

(a)

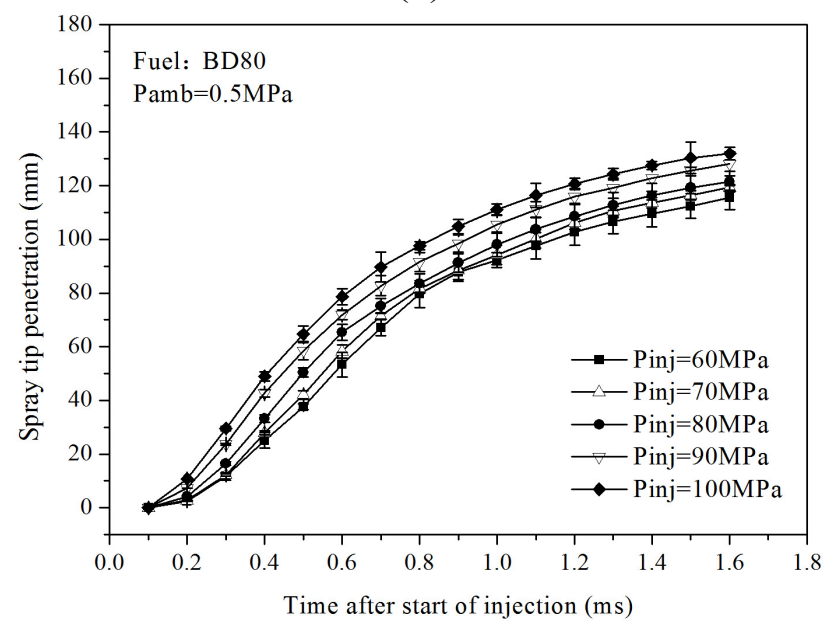

(c)

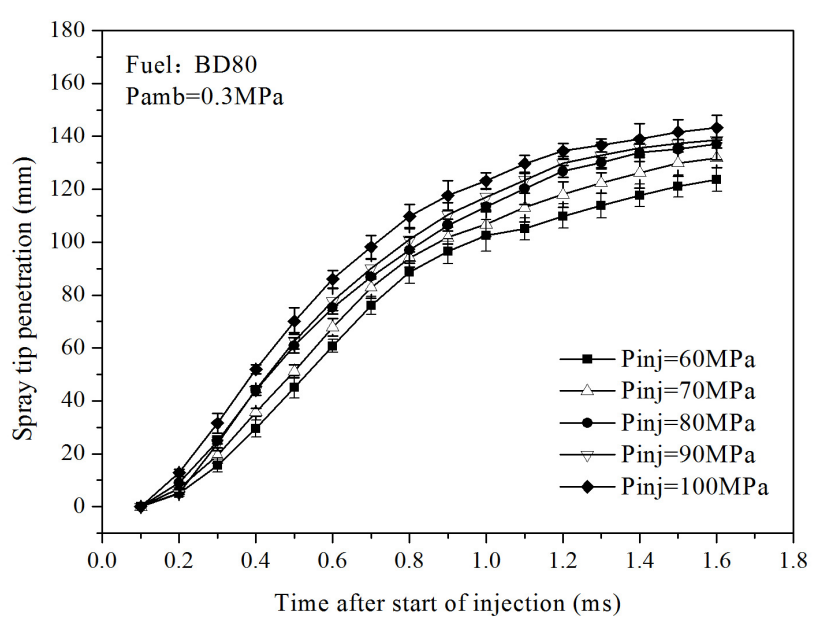

(b)

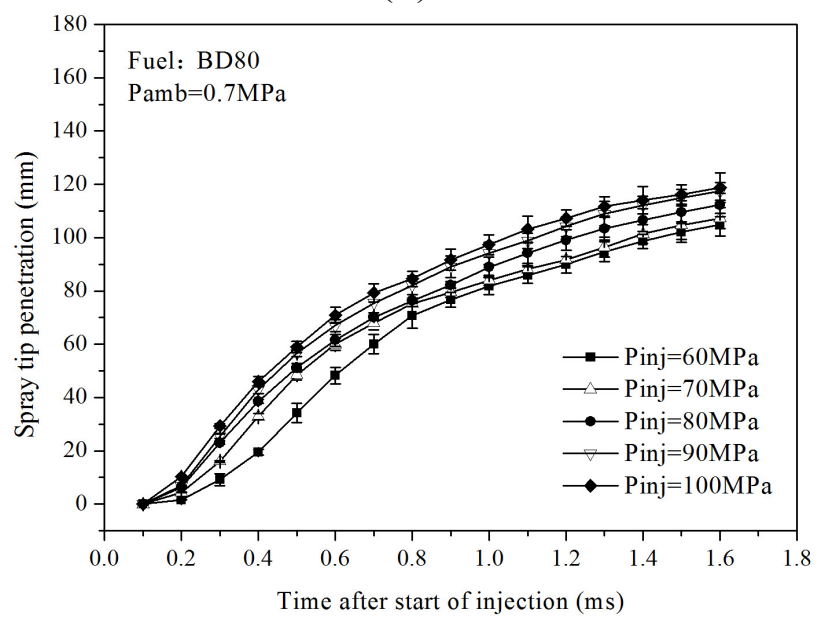

(d)

Figure 2. Cont. 


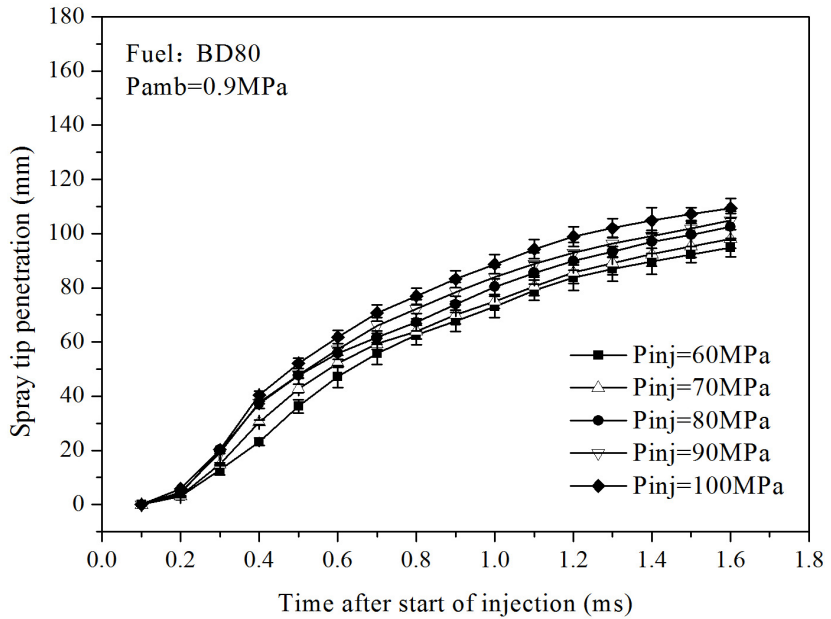

(e)

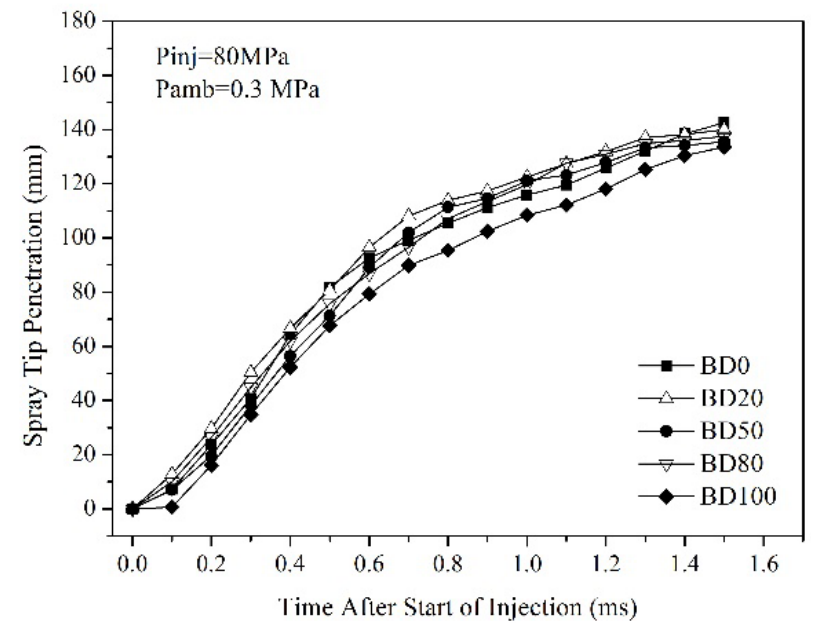

$(\mathbf{g})$

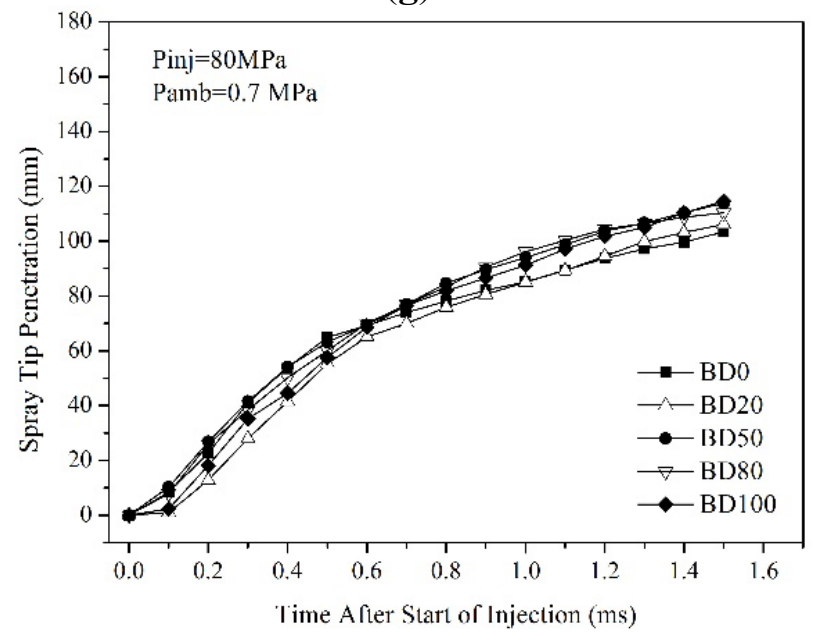

(i)

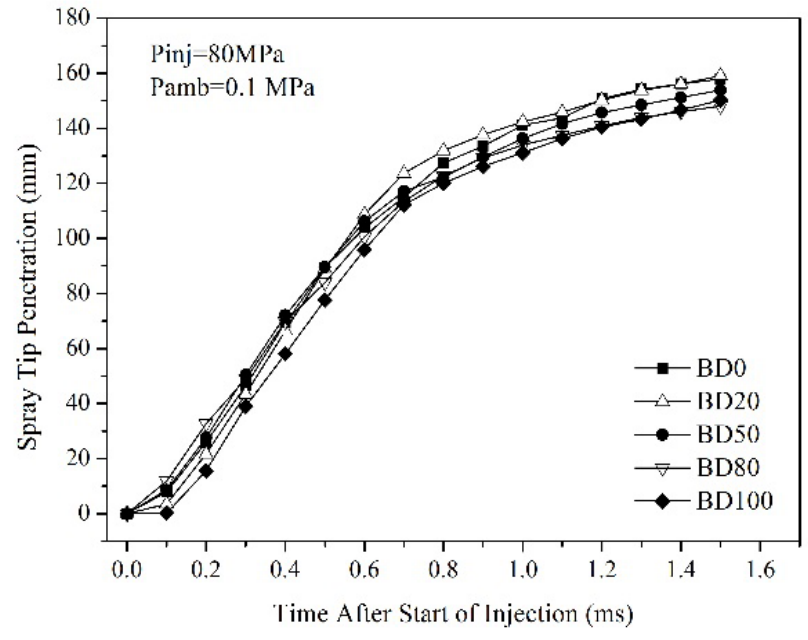

(f)

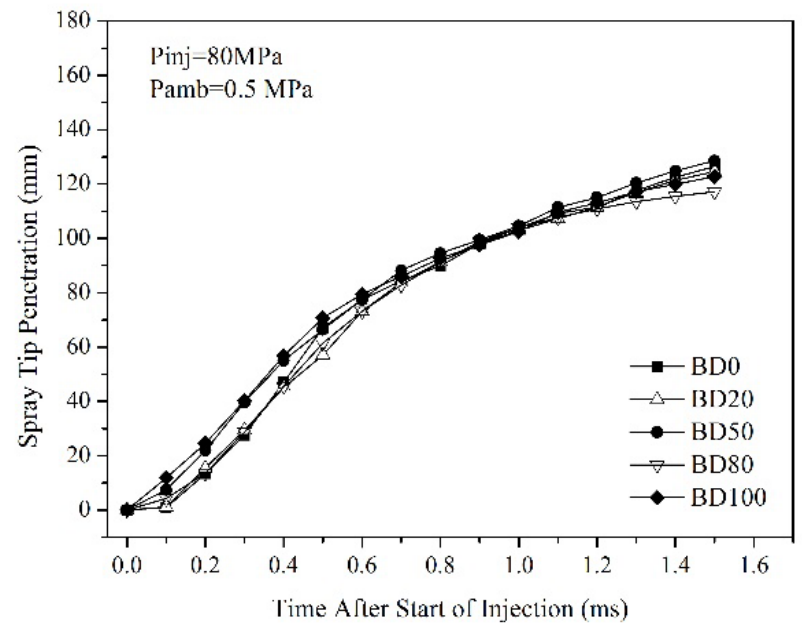

(h)

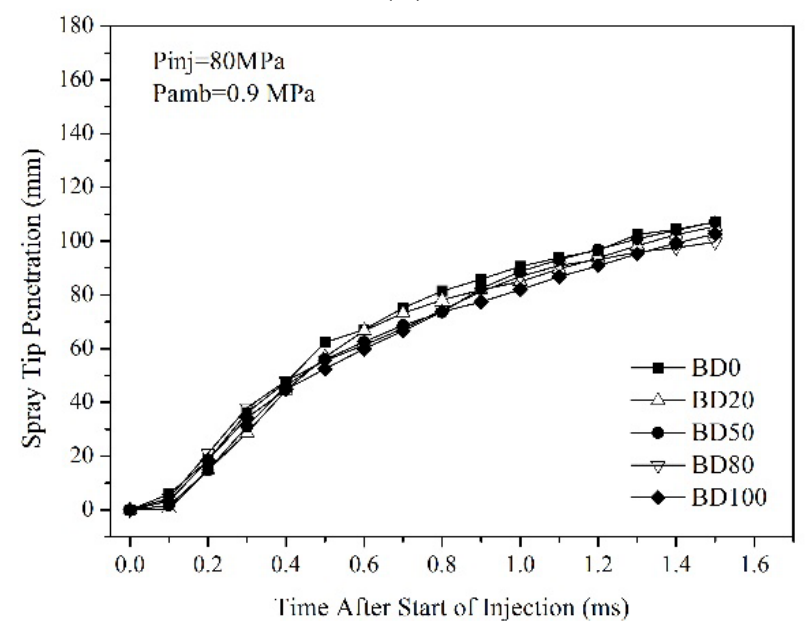

(j)

Figure 2. Spray tip penetration for different fuels under different ambient pressures. Spray tip penetration of BD80 at different injection pressures: (a) Pamb $=0.1 \mathrm{MPa}$; (b) Pamb $=0.3 \mathrm{MPa}$; (c) $\mathrm{Pamb}=0.5 \mathrm{MPa}$; (d) $\mathrm{Pamb}=0.7 \mathrm{MPa}$; (e) Pamb $=0.9 \mathrm{MPa}$. Spray tip penetration of different fuels at injection pressure $80 \mathrm{MPa}$ : (f) Pamb $=0.1 \mathrm{MPa}$; (g) Pamb $=0.3 \mathrm{MPa}$; (h) $\mathrm{Pamb}=0.5 \mathrm{MPa}$; (i) Pamb =0.7 MPa; (j) Pamb =0.9 MPa. 
We compared the spray tip penetration of diesel measured by us with the experimental results of Lee [25] under the ambient pressure of $0.1 \mathrm{MPa}$ and 60 and $80 \mathrm{MPa}$ injection pressure, and the results are presented in Figure 3a. They indicated that our experimental spray tip penetration showed a similar evolution trend as Lee's, and the results we measured were a little shorter than Lee's, which may be caused by the different light intensity threshold values. Based on these results, it can be seen that the spray tip penetrated faster with a higher injection pressure under a certain ambient pressure. Figure $3 \mathrm{~b}$ shows a comparison between our experimental spray tip penetration results for diesel and the results predicted by Hiroyasu and Arai using empirical equations [26]. The comparison was at 60, 70, $80,90,100 \mathrm{MPa}$ injection pressure and $0.3 \mathrm{MPa}$ ambient pressure. We can see that the measured spray tip penetration was shorter than that suggested by Hiroyasu and Arai [26] for the initial spray injection time for the first $0.4 \mathrm{~ms}$ after the start of injection, while the experimental results were larger after $0.6 \mathrm{~ms}$. The experimental results of the whole penetration also showed a similar trend with the empirical equation values suggested by Hiroyasu and Arai.

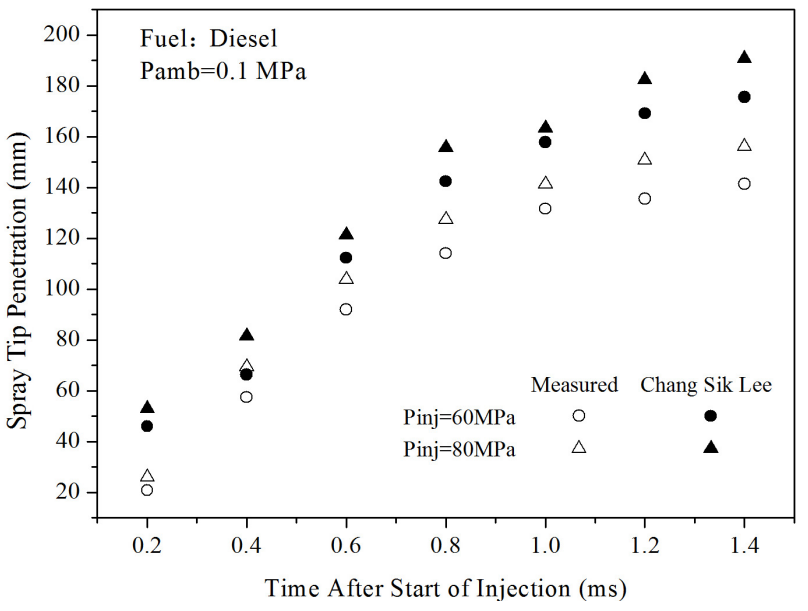

(a)

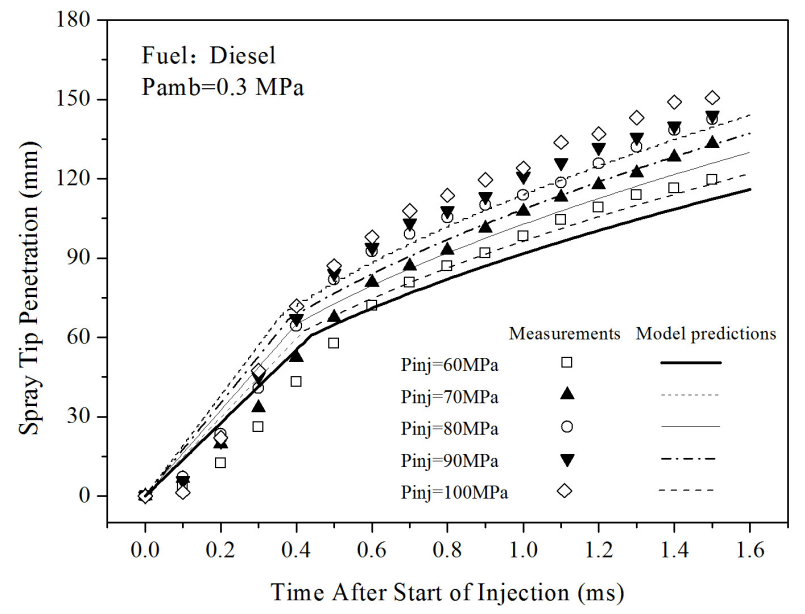

(b)

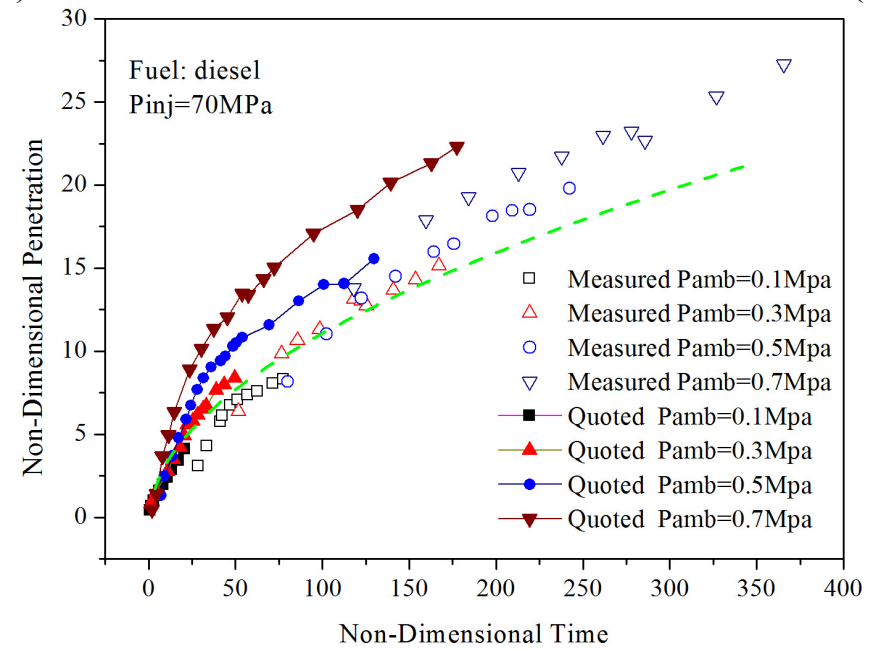

(c)

Figure 3. Comparison of spray tip penetration for experimental results and empirical equations. (a) Compared with the experimental result obtained by Lee and Park [25]; (b) compared with the empirical equation data of Hiroyasu and Arai [26]; (c) non-dimensional penetration versus non-dimensional time (the dashed line was obtained from Equation (1)). 
Equation (1), given by Naber and Siebers [27], concerns the non-dimensional penetration versus non-dimensional time:

$$
\tilde{s}=\left[\left(\frac{1}{\tilde{t}}\right)^{n}+\left(\frac{1}{\tilde{t}^{0.5}}\right)^{n}\right]^{\frac{-1}{n}}
$$

In the correlation, $n$ is a model constant, $\tilde{s}$ and $\tilde{t}$ are the dimensionless penetration and dimensionless time, respectively, defined by Equations (2) and (3):

$$
\begin{aligned}
& \tilde{s}=\frac{s}{x^{+}} \\
& \tilde{t}=\frac{t}{t^{+}}
\end{aligned}
$$

$t^{+}$was the time scale and $x^{+}$was the length scale, which could be obtained by the following Equations (4) and (5):

$$
\begin{gathered}
x^{+}=\frac{C_{a}^{0.5} d_{o} \sqrt{\frac{\rho_{l}}{\rho_{g}}}}{\tan (\theta)} \\
t^{+}=\frac{C_{a}^{0.5} d_{o} \sqrt{\frac{\rho_{l}}{\rho_{g}}}}{\tan (\theta) V_{i n j}}
\end{gathered}
$$

where $\rho_{l}$ and $\rho_{g}$ are the fuel and gas density, $d_{o}$ is the nozzle diameter, $C_{a}$ is area-contraction coefficient, $V_{i n j}$ is the injection velocity, $\theta$ is the spray angle.

Through this non-dimensional correlation, we compared experimental results from different diesel equipment for under an injection pressure of $70 \mathrm{MPa}$ and four ambient pressures $(0.1,0.3,0.5,0.7 \mathrm{MPa})$. Figure 3c shows the comparison of penetration for our results (symbols), results (solid lines) quoted from Roisman [28], and the results (dashed lines) obtained from Equation (1), showing good agreement.

\subsection{Average Tip Velocity at Penetration}

The fluctuating injection pressure caused by the needle movement and time inside the high-pressure pipeline produced a fluctuation of spray tip speed [22]. Because of the resulting variation in velocity in the axis of travel like instantaneous speed, the average spray velocity, which could be easily obtained, is discussed in this study.

The average tip velocity at penetration for BD80 is presented in Figure 4a-e, which were obtained by the specific value of difference in penetration and time interval between two consecutive spray images. The average spray velocity showed a sharp increase up to about $200 \mathrm{~m} / \mathrm{s}$ following the start of injection. Then it decreased rapidly to $20-40 \mathrm{~m} / \mathrm{s}$ after the peak velocity and finally remained stable after $1.3 \mathrm{~ms}$. This trend can be easily observed in Figure 4. For the process after the peak value, the trend of spray velocity was consistent with the predictions proposed by Delacourt et al. [16]. 


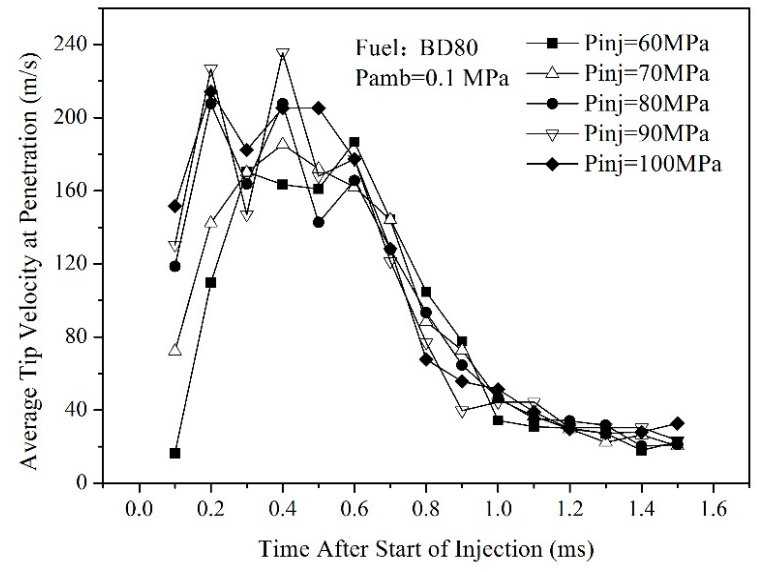

(a)

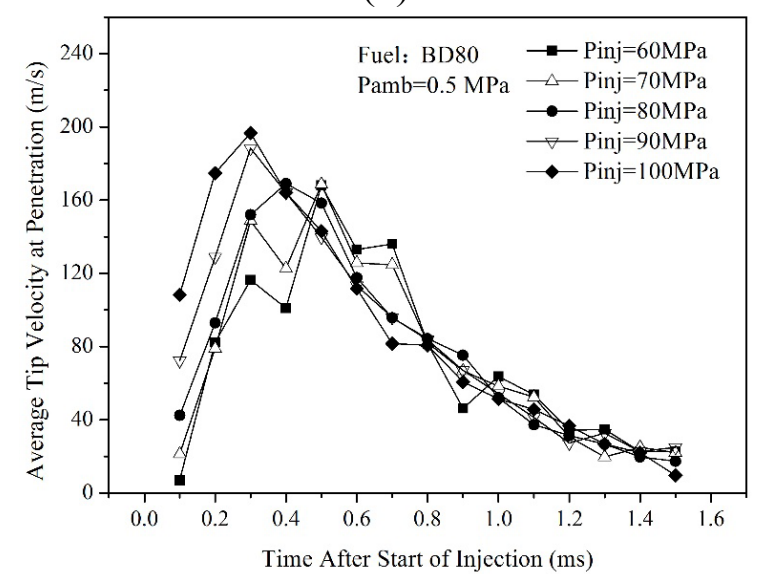

(c)

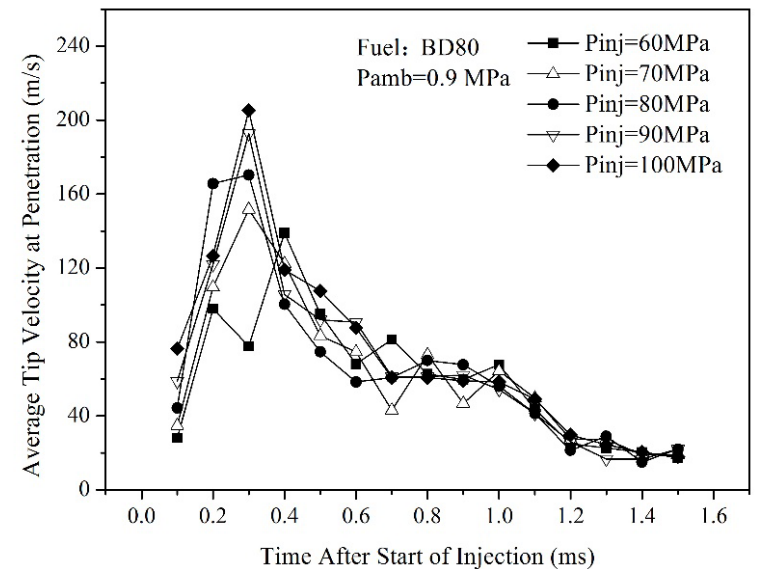

(e)

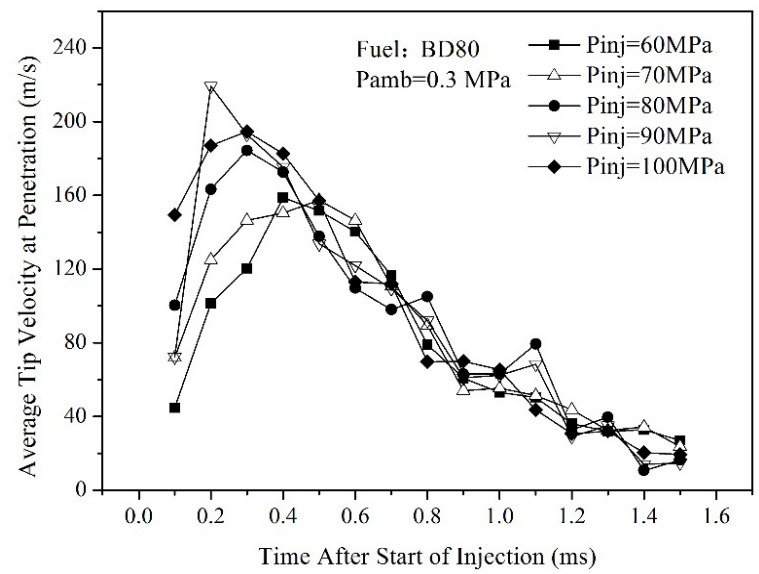

(b)

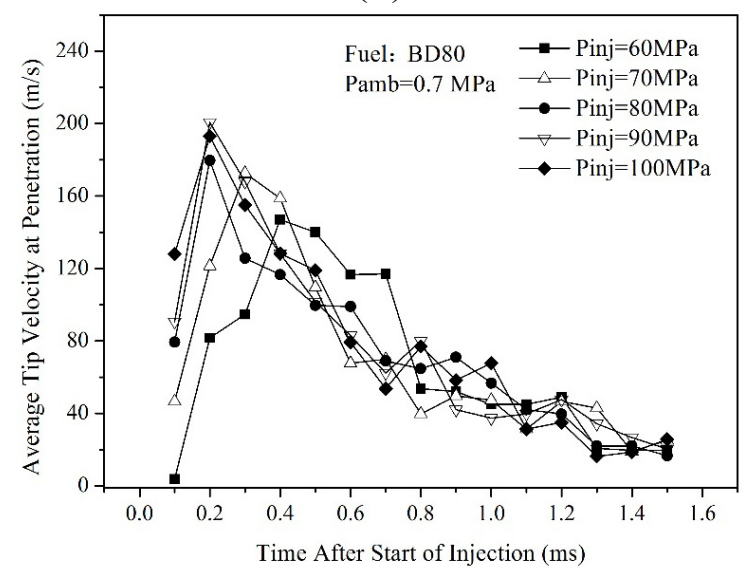

(d)

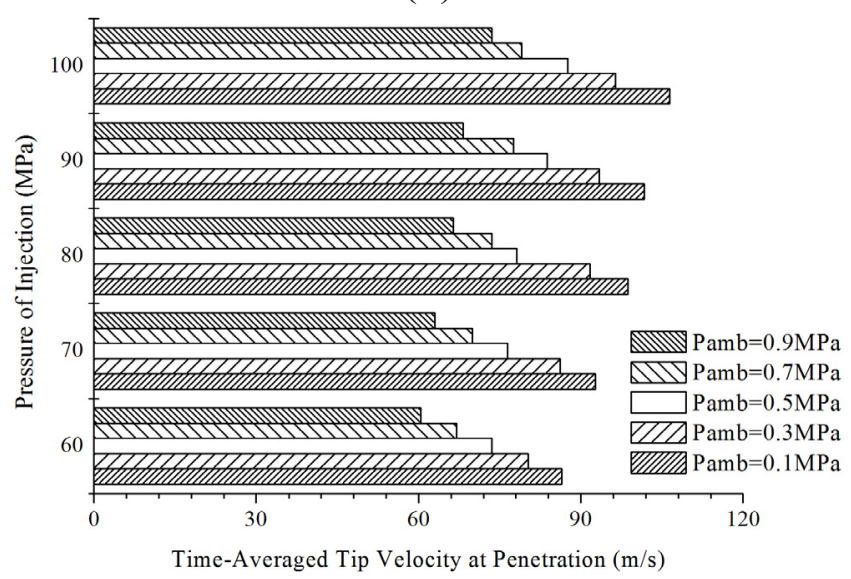

(f)

Figure 4. The average tip velocity under different ambient pressures (BD80): (a) Pamb $=0.1 \mathrm{MPa}$; (b) Pamb $=0.3 \mathrm{MPa}$; (c) Pamb $=0.5 \mathrm{MPa}$; (d) Pamb = $0.7 \mathrm{MPa}$; (e) Pamb $=0.9 \mathrm{MPa}$; (f) the time-averaged tip velocity at penetration under different injection pressures and ambient pressures.

Regardless of the similar stable phases, the average spray velocity roughly increased with the increasing injection pressure, which acted as the source of spray kinetic energy providing the penetrating power. Comparing the curves under different ambient pressures, it can be noted that the average spray velocity decreased for all the injection pressures with the increase of ambient pressure. This can be 
attributed to the fact that with the increase of the ambient pressure, an increase in chamber air density resulting in a higher resistance to the spray evolution was observed. The fluctuating injection pressure generated by the moving grids from needle opening to closure may be the reason why a few sudden decreases appeared at the peak values. The regained high speed could be from the collision between the subsequent spray droplets with high kinetic energy and the previous spray droplets.

The time-averaged tip velocity at penetration for BD80 is presented in Figure 4f, which was obtained by the average of all the average tip velocity at penetration under the same condition. As clearly shown in Figure 4f, the time-averaged tip velocity at penetration increased with the increasing injection pressure and decreased as the ambient pressure became higher, indicating that the tip velocity was accelerated by the injection pressure and hindered by the ambient pressure.

\subsection{Spray Angle}

The spray angle is defined as the angle between the two tangent lines which delineate the approximate spray boundaries at half of the tip penetration from the discharge orifice [18], as shown in Figure 1b. The spray angle is an important parameter to assess the spray quality, as it represents the spray development in the radial direction. Considering the fact that the spray angle during a pulsating injection kept quite stable with elapsed time, only the spray angle for BD80 under three ambient pressures $(0.1,0.5$ and $0.9 \mathrm{MPa}$ ) is shown in Figure 5. Due to the quite stable spray angle, the trend of spray angle was same as that of the average angle, which would be discussed subsequently.
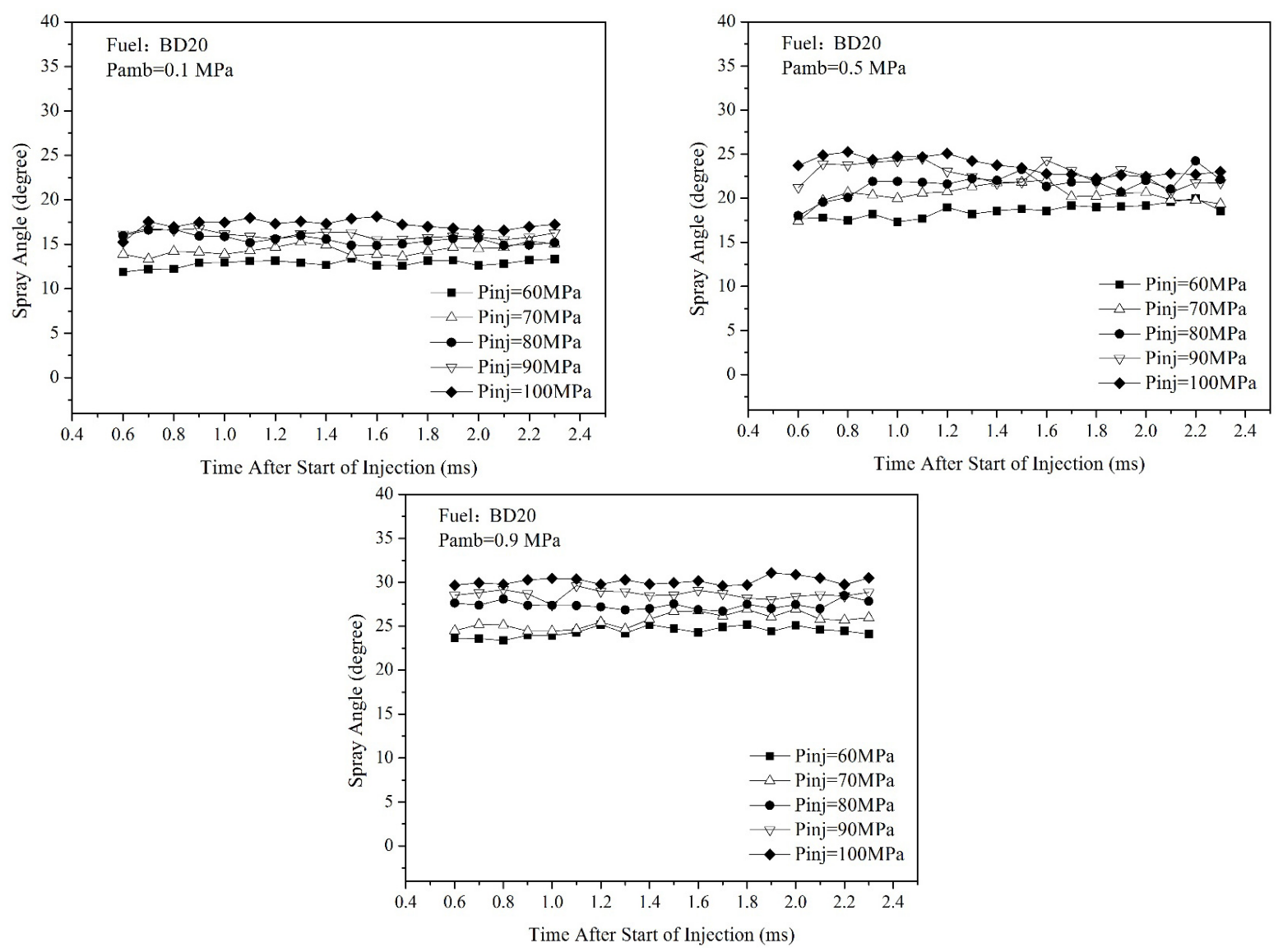

Figure 5. The spray angle for BD80 at different ambient pressures. 


\subsection{Average Spray Angle}

The average spray angle is the average of all the angles obtained from the effective images during a pulsating injection. The average angle for biodiesel and blends with respect to diesel spray for all conditions is illustrated in Figure 6. For all the blend ratios, the average angle increased slightly with an increase in injection pressure, but significantly with the increasing ambient pressure.
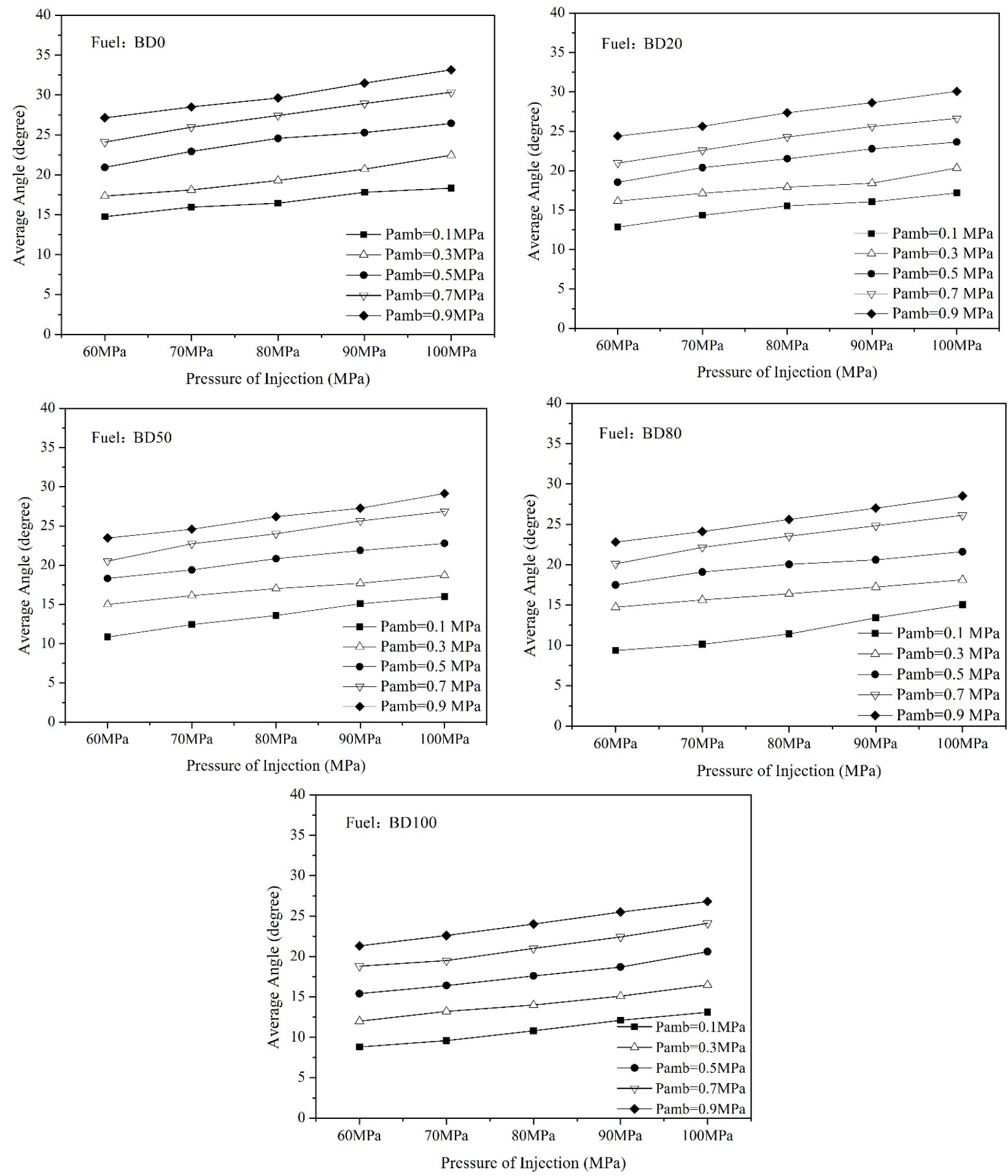

Figure 6. The average angle for all conditions. 
The increasing injection pressure strengthened the spray dispersion and secondary pulverization, which promoted the spray process both in the axial and radial directions. However, the advance along the axis was conspicuously faster than the radial spread, resulting in a slight increase of spray angle. The increase of pressure in the constant volume chamber led to a higher ambient density enhancing the resistance to fuel spray. Therefore, the spray development in the axial direction was severely inhibited [29], which forced the ever-increasing mass flow to spread in the radial direction, leading to a remarkable increase in spray angle.

Comparing the curves for different fuels, the average spray angle decreased slightly as the ratio of the biodiesel became higher, and the spray angle of BD100 remained the smallest under all conditions. The comparatively higher viscosity and surface tension of biodiesel compared with that of diesel contributed to the trend through preventing the breakup of the liquid jet. The viscosity and surface tension of the blend fuels increased in accordance with the mixing ratio of the biodiesel, thus it was more difficult to atomize the blends. Therefore, the extension in the horizontal direction was impeded, resulting in a slight decrease in the spray angle.

\subsection{Spray Evolution Process}

The spray evolution and development of all fuels after start of injection (SOI) under all conditions are arranged in Figure 7, where the effect of blend ratio, injection pressure and ambient pressure are presented in Figure $7 \mathrm{a}-\mathrm{c}$, respectively. The spray penetrated along the axis in a downward direction from the nozzle tip with the elapsed time, accompanied by the growth of spray tip penetration and spray area.

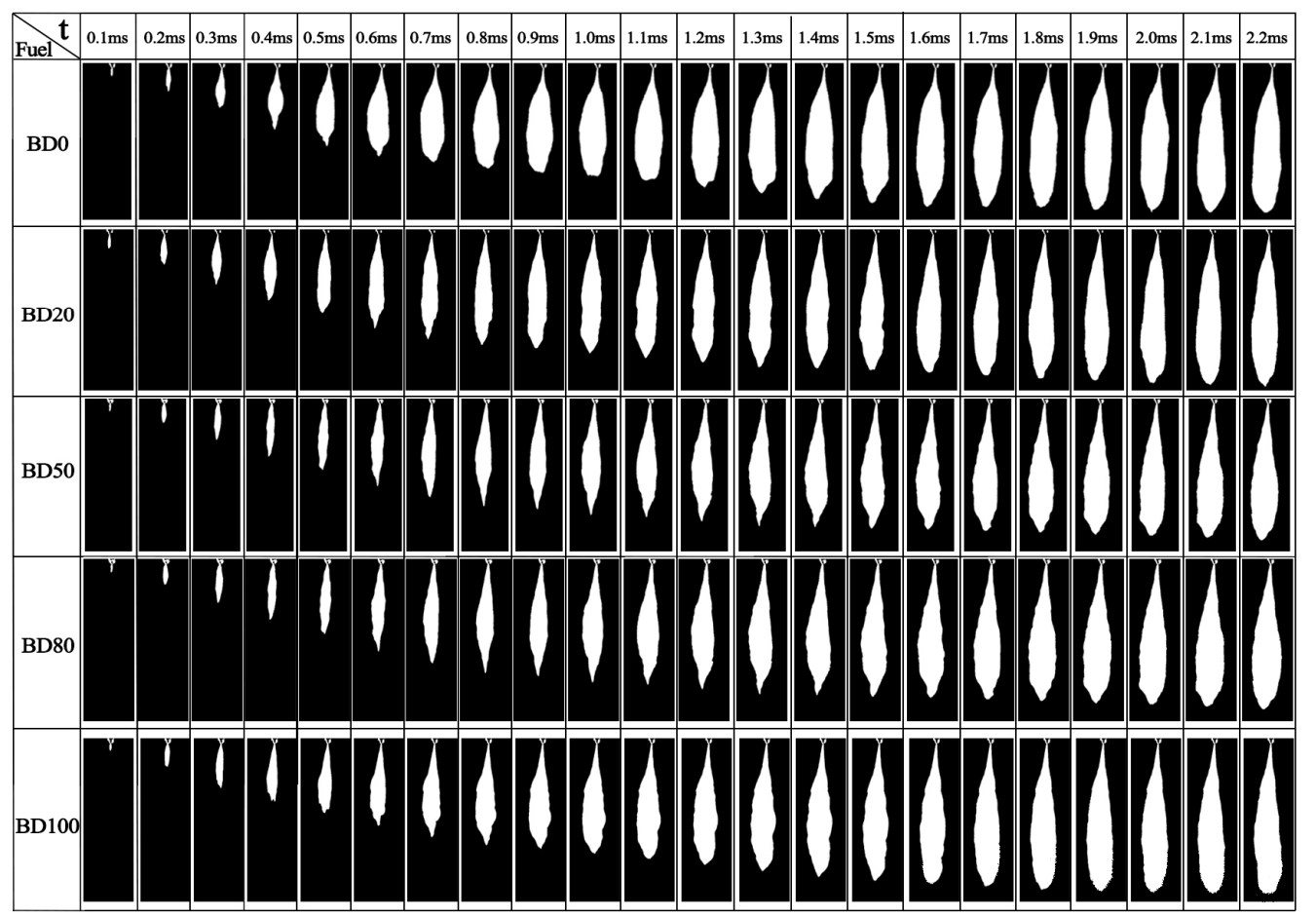

(a)

Figure 7. Cont. 


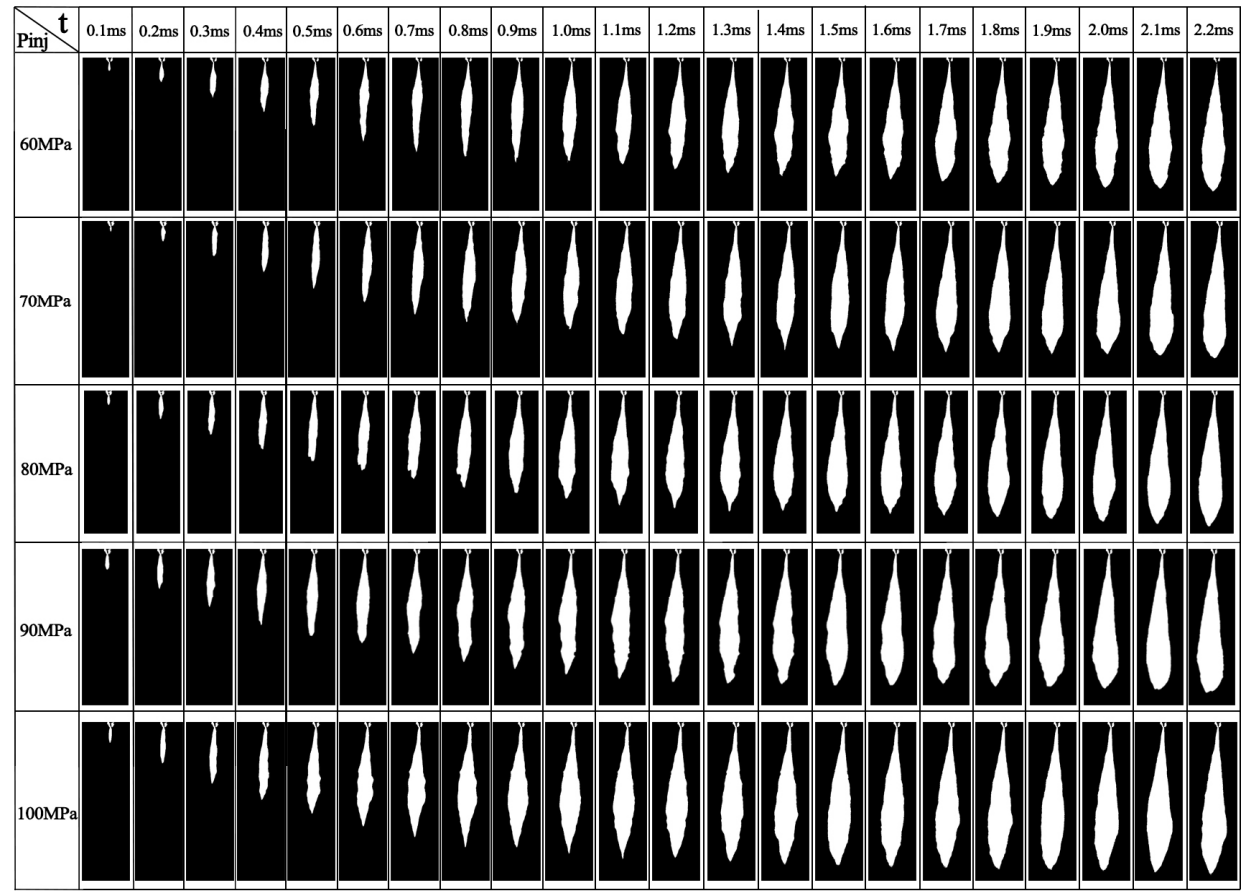

(b)

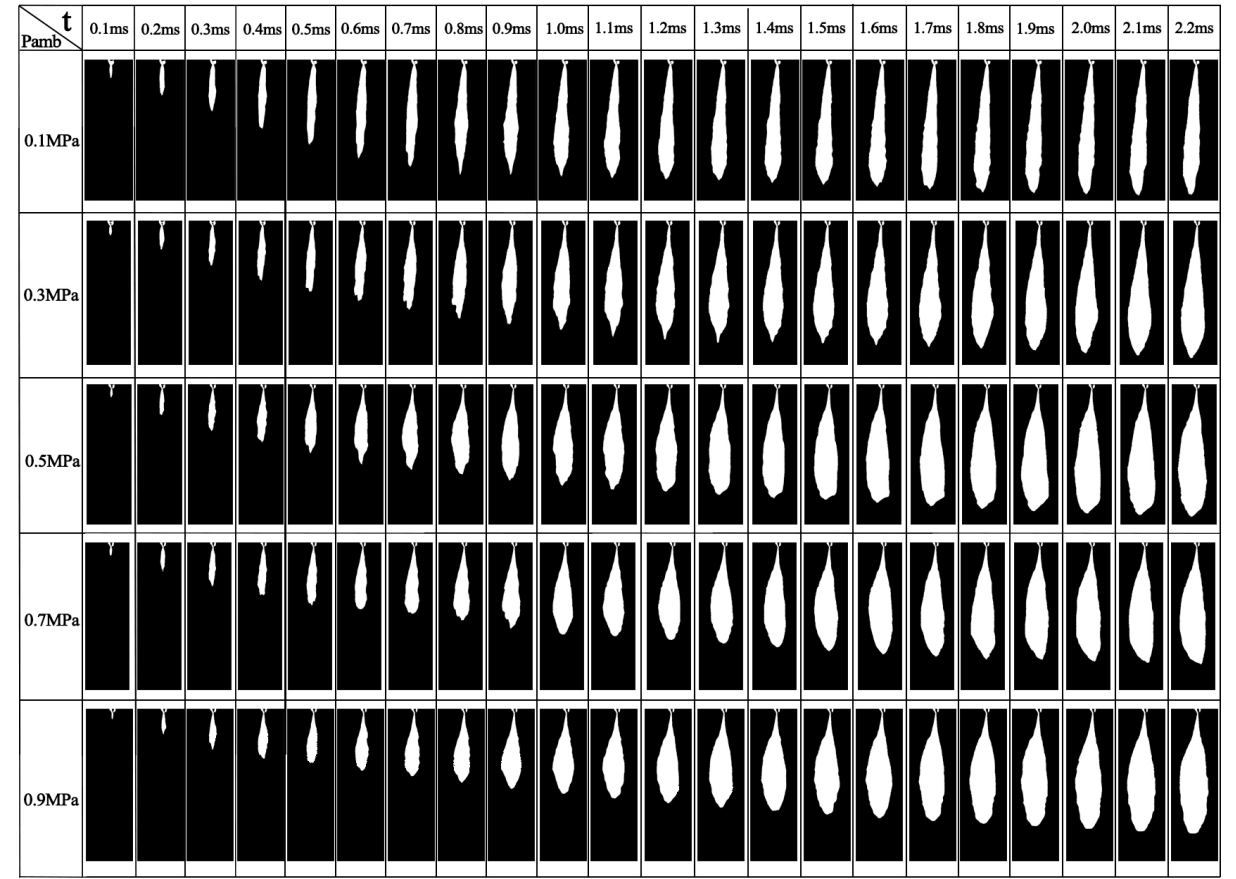

(c)

Figure 7. Spray evolution processes of the fuels after SOI for all conditions. (a) Pamb $=0.3 \mathrm{MPa}$, Pinj = 80 MPa; (b) Fuel: BD80, Pamb =0.3 MPa; (c) Fuel: BD80, Pinj $=80 \mathrm{MPa} ; t$, Time after start of injection (SOI).

As shown in Figure 7a, the spray characteristics for different blend ratios developed similarly with the elapsed time, and reached a stable stage at the similar time. The angle of BD0 and the tip penetration of BD20 were a little larger compared with the other fuels, due to the higher viscosity and surface tension of biodiesel leading to a smaller spray angle. This indicated that the blend ratio had little influence on the spray morphology. 
Figure $7 \mathrm{~b}$ shows that the spray tip penetration and spray area evolved faster with a higher injection pressure resulting in a better atomization quality. This was because disintegrated small droplets gained higher momentum at higher injection pressures, which induced an extension of the spray area primarily due to the longer spray tip penetration.

From Figure 7c, we can see that the ambient pressure had a significant effect on the spray characteristics. The spray shape became remarkably shorter and wider as the ambient pressure increased. This was because that the increased ambient pressure raised the ambient gas density, which enhanced the resistance against penetration resulting in the shorter penetration. As discussed previously, while the jet penetrated slower, the rapid increase of flow forced the atomization to extend in radial direction, then the spray angle increased significantly. Under the ambient pressure $0.1 \mathrm{MPa}$, the penetration reached stability after $0.8 \mathrm{~ms}$, while that time was delayed to about $1.5 \mathrm{~ms}$ under $0.9 \mathrm{MPa}$. It was obvious that the stable stage was delayed with the increasing ambient pressure.

\subsection{Spray Area}

The spray area is the area covered by the spray in the effective images, which can be employed to reflect the quality of fuel-air mixing [13]. The spray area was obtained from the sum of the total effective pixels, and the spray area for BD80 is shown in Figure 8. The abscissa axis was set as spray tip penetration instead of time after SOI for the purpose of eliminating the influence of injection timing on spray area.
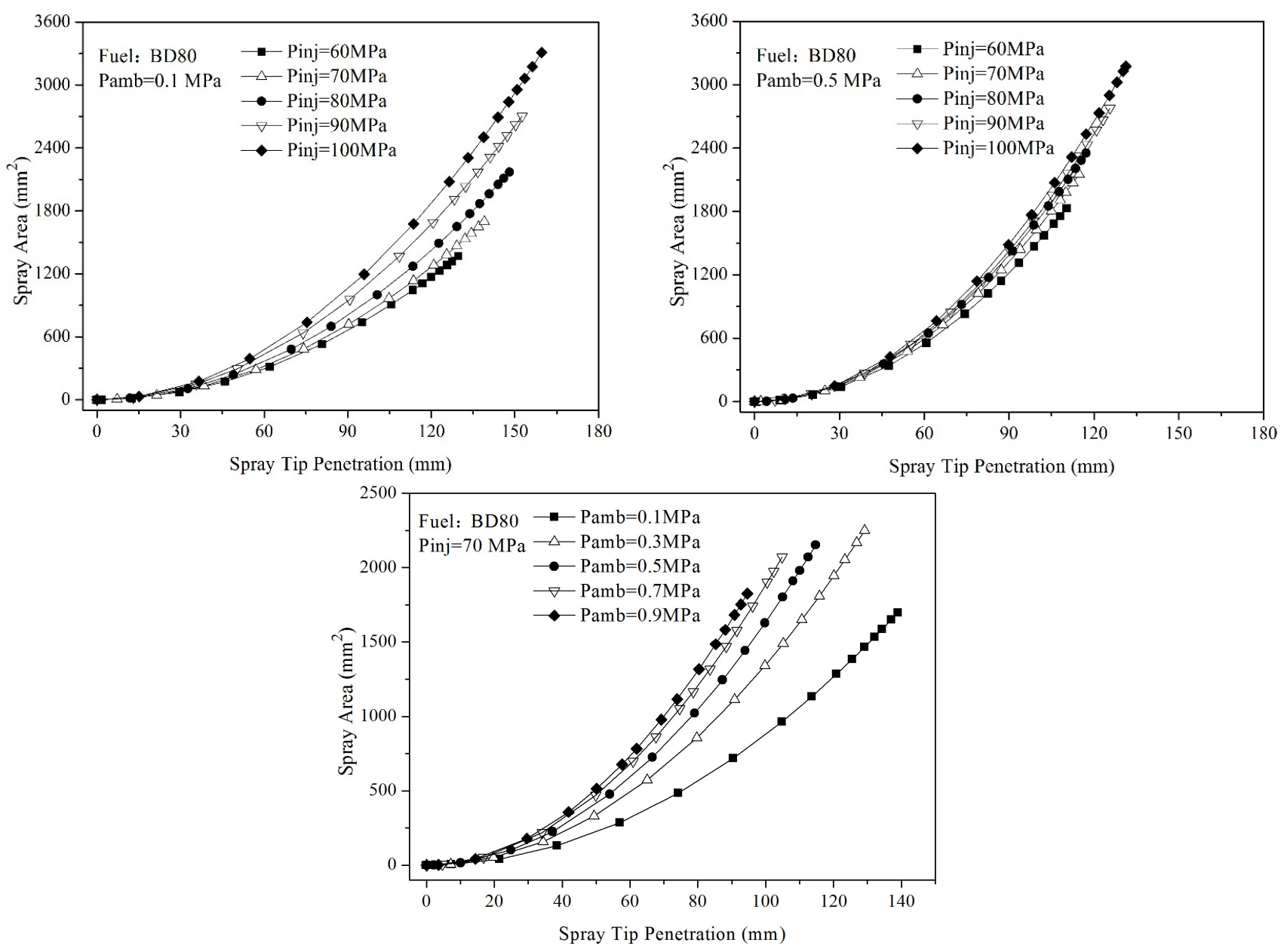

Figure 8. The spray area for BD80 under different pressures. 
The spray area developed as exponential curves with spray tip penetration. From Figure 8a, it can be seen clearly that the spray area increased with the increase of injection pressure due to the enlargement both in spray tip penetration and spray angle, as discussed previously. Comparing Figure 8a,b, it was clear that the difference between spray areas at different injection pressures decreased significantly with the increasing ambient pressure. As shown in Figure 8c, identical tip penetration corresponded to a larger spray area with the increase of ambient pressure. This was mainly because the higher resistance produced by increasing ambient pressure forced the droplets to move radially outwards instead of forward, resulting in a larger spray angle. At the same time point, the spray area increased from 0.1 to $0.3 \mathrm{MPa}$ due to the increasing spray angle resulting from the increasing flow through the nozzle, but decreased from 0.3 to $0.9 \mathrm{MPa}$ gradually, as the continuously increasing ambient pressure restrained the development of both spray tip penetration and spray angle.

\subsection{Spray Volume}

The spray volume was the volume of atomization, which acted an important role in evaluating the quality of fuel-air mixing. The spray volume was calculated through the following equation [16]:

$$
V=(\pi / 3) S^{3}\left[\tan ^{2}(\theta / 2)\right] \frac{1+2 \tan (\theta / 2)}{[1+\tan (\theta / 2)]^{3}}
$$

In the above equation, $S$ is the spray tip penetration and $\theta$ is the spray angle. The calculated spray volume for BD80 is shown in Figure 9. To eliminate the influence of injection timing on spray volume, instead of time after SOI, the spray tip penetration acted as the abscissa axis.

The spray volume developed as exponential curves with spray tip penetration, faster than the spray area. It was indicated from Figure 9a that under a certain ambient pressure, the higher the injection pressure was, the larger the spray volume presented at the same tip penetration. This was because that the increasing injection pressure pushed forward the jet as well as strengthened the atomization, resulting in the longer tip penetration and larger spray angle, and then further increased the spray volume. Combining Figure 9a,b, we can see that as the ambient pressure increased, the difference of volumes between different injection pressures decreased significantly. As shown in Figure 9c, when the ambient pressure increased, the same spray volume corresponded to a shorter tip penetration, which was mainly caused by the larger spray angle under a higher ambient pressure. For the same time point, the spray volume increased from 0.1 to $0.5 \mathrm{MPa}$, but decreased from 0.5 to $0.9 \mathrm{MPa}$ gradually. This may be because that the increasing flow led to an increase of the spray angle at early pressurization, however, as time elapsed, the continuously increasing ambient pressure impeded both penetrating and break-up of the jet, and further leading to the decrease of spray volume at the same time point. 


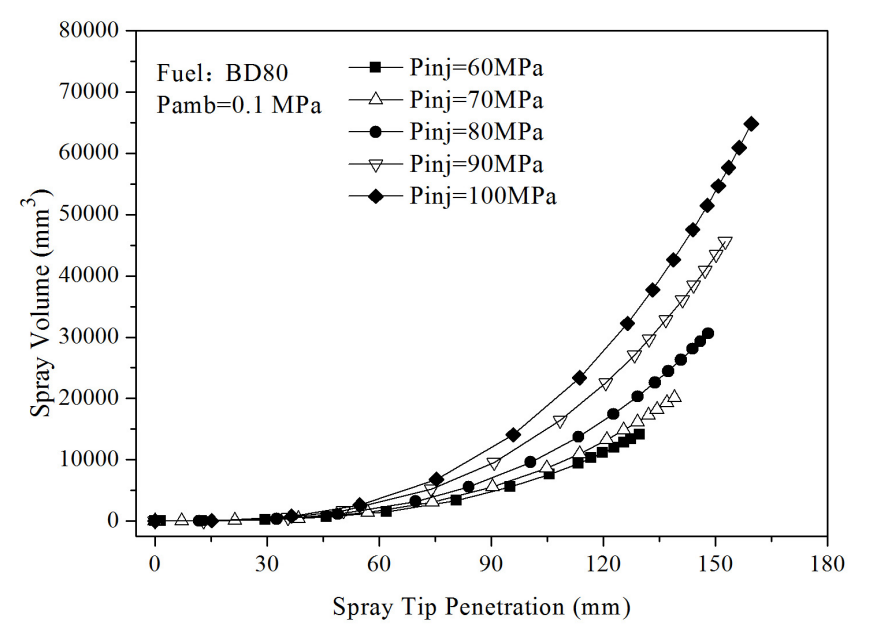

(a)

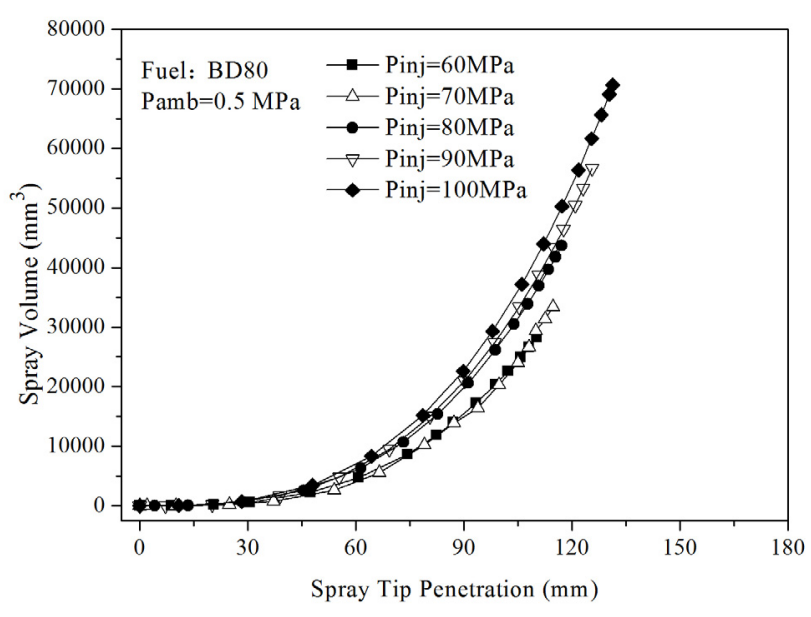

(b)

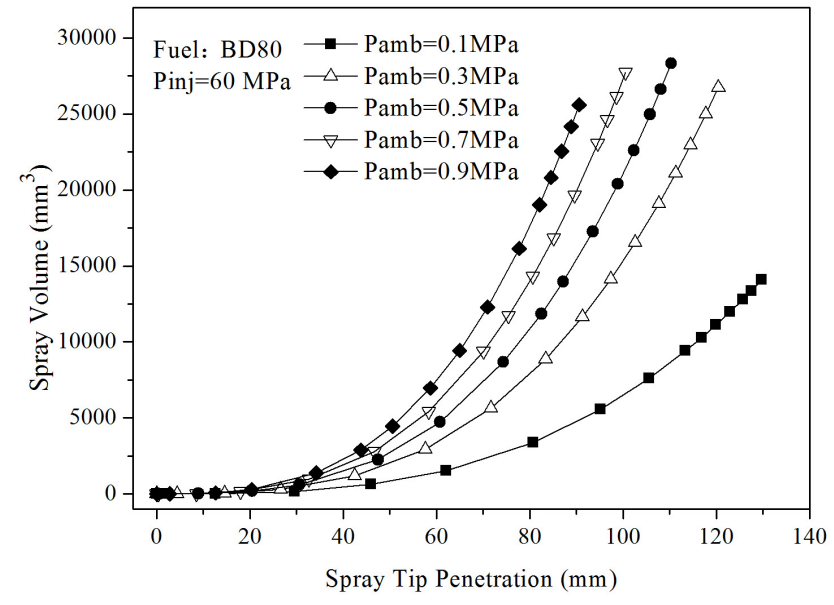

(c)

Figure 9. The spray volume for BD80 under different pressures.

\section{Conclusions}

Experimental macroscopic spray characteristics of biodiesel derived from drainage oil and its BD0, BD20, BD50, BD80, BD100 blends with diesel were obtained under different injection pressures and ambient pressure conditions in a constant volume spray chamber. The characteristic data was extracted from the spray images grabbed by a high speed visualization system. Based on the results of this study, we can make the following observations:

(1) The spray tip penetration, peak of average tip velocity, spray area and spray volume increased with the increase of the injection pressure. The spray angle and average angle were insensitive to the injection pressure and showed a slight increase.

(2) The spray tip penetration, and peak average tip velocity decreased with the increase of the ambient pressure. The spray angle, average angle increased significantly with the increasing ambient pressure, resulting in a shorter and wider spray shape.

(3) The spray tip penetration presented little variation with the increase of the blend ratio. However, the spray angle and average angle decreased slightly, and the spray shape became narrower. $100 \%$ diesel gave a larger spray angle and average angle compared with other fuels. 
(4) As time elapsed, the spray tip penetration increased rapidly during the early injection stage followed by a gradual smoothing process later, the spray angle remained stable, the spray shape became longer and wider, and the average tip velocity presented a sharp increase following SOI, then decreased rapidly after the peak spray tip velocity and finally remained stable.

(5) The spray area and spray volume increased significantly with the increasing spray tip penetration.

(6) Among the physical properties affecting the spray characteristics, viscosity and surface tension were main ones, which inhibited the breakup of liquid jet and atomization. In the present study, viscosity and surface tension of the blend fuels increased with the increase of blend ratio.

\section{Acknowledgments}

This work is supported by National Natural Science Foundation of China (No. 51376171), and National Key Basic Research Program (No. 2010CB227300) founded by MOST (Ministry of Science and Technology).

\section{Author Contributions}

All authors contributed to this work. Hongzhan Xie is the first author. Hongzhan Xie designed the study and contributed to the experiments and writing the manuscript. Lanbo Song, Yizhi Xie, Dong Pi and Chunyu Shao contributed to designing the experimental setup and the analysis. The whole project was supervised by Qizhao Lin.

\section{Conflicts of Interest}

The authors declare no conflict of interest.

\section{References}

1. Basak, A.; Patra, J.; Ganguly, R.; Datta, A. Effect of transesterification of vegetable oil on liquid flow number and spray cone angle for pressure and twin fluid atomizers. Fuel 2013, 112, 347-354.

2. Dong, Y.Q.; Liu, Y.X. Present situation and future of biodiesel. Mod. Veh. Power 2007, 4, 1-9.

3. Chhetri, A.B.; Watts, K.C.; Islam, M.R. Waste cooking oil as an alternate feedstock for biodiesel production. Energies 2008, 1, 3-18.

4. Kuti, O.A.; Nishida, K.; Zhu, J.Y. Experimental studies on spray and gas entrainment characteristics of biodiesel fuel: Implications of gas entrained and fuel oxygen content on soot formation. Energy 2013, 57, 434-442.

5. Pandey, R.K.; Rehman, A.; Sarviya, R.M. Impact of alternative fuel properties on fuel spray behavior and atomization. Renew. Sustain. Energy Rev. 2012, 16, 1762-1778.

6. Kim, H.; Kim, Y.; Lee, K. An Experimental study on the spray, combustion, and emission characteristics of two types of biodiesel fuel. Energy Fuels 2013, 27, 5182-5191.

7. Badreldin, A.M. Automatic analysis of fuel spray images. Comput. Ind. 1987, 9, 107-113.

8. Som, S.; Longman, D.E.; Ramirez, A.I.; Aggarwal, S.K. A comparison of injector flow and spray characteristics of biodiesel with petrodiesel. Fuel 2010, 89, 4014-4024. 
9. Boggavarapu, P.; Ravikrishna, R.V. A review on atomization and sprays of biofuels for IC engine applications. Int. J. Spray Combust. Dyn. 2013, 5, 85-121.

10. Battistoni, M.; Grimaldi, C.N. Numerical analysis of injector flow and spray characteristics from diesel injectors using fossil and biodiesel fuels. Appl. Energy 2012, 97, 656-666.

11. Wang, X.G.; Huang, Z.H.; Kuti, O.A.; Zhang, W.; Nishida, K. Experimental and analytical study on biodiesel and diesel spray characteristics under ultra-high injection pressure. Int. J. Heat Fluid Flow 2010, 31, 659-666.

12. Yoon, S.H.; Park, S.H.; Lee, C.S. Experimental investigation on the fuel properties of biodiesel and its blends at various temperatures. Energy Fuels 2008, 22, 652-656.

13. Yuan, W.; Hansen, A.C.; Zhang, Q. Predicting the temperature dependent viscosity of biodiesel fuels. Fuel 2008, 88, 1120-1126.

14. Pan, J.F.; Yang, W.M.; Chou, S.; Li, D.T.; Xue, H.; Zhao, J.G.; Tang, A.K. Spray and combustion visualization of biodiesel in a direct injection diesel engine. Therm. Sci. 2013, 17, 279-289.

15. Agarwal, A.K.; Dhar, A.; Gupta, J.G.; Kim, W.I.; Lee, C.S.; Park, S. Effect of fuel injection pressure and injection timing on spray characteristics and particulate size-number distribution in a biodiesel fuelled common rail direct injection diesel engine. Appl. Energy 2014, 130, 212-221.

16. Delacourt, E.; Desmet, B.; Besson, B. Characterization of very high pressure diesel sprays using digital imaging techniques. Fuel 2005, 84, 859-867.

17. Agarwal, A.K.; Chaudhury, V.H. Spray characteristics of biodiesel/blends in a high pressure constant volume spray chamber. Exp. Therm. Fluid Sci. 2012, 42, 212-218.

18. Kim, H.J.; Park, S.H.; Lee, C.S. A study on the macroscopic spray behavior and atomization characteristics of biodiesel and dimethyl ether sprays under increased ambient pressure. Fuel Process. Technol. 2010, 91, 354-363.

19. Chen, P.C.; Wang, W.C.; Roberts, W.L.; Fang, T.G. Spray and atomization of diesel fuel and its alternatives from a single-hole injector using a common rail fuel injection system. Fuel 2013, 103, 850-861.

20. Mohan, B.; Yang, W.M.; Tay, K.L.; Yu, W.B. Experimental study of spray characteristics of biodiesel derived from waste cooking oil. Energy Convers. Manag. 2014, 88, 622-632.

21. Lee, C.S.; Park, S.W.; Kwon, S.I. An experimental study on the atomization and combustion characteristics of biodiesel-blended fuels. Energy Fuels 2005, 19, 2201-2208.

22. Gao, Y.; Deng, J.; Li, C.W.; Dang, F.L.; Liao, Z.; Wu, Z.J.; Li, L.G. Experimental study of the spray characteristics of biodiesel based on inedible oil. Biotechnol. Adv. 2009, 27, 616-624.

23. Srichai, P.; Chareonphonphanich, C.; Karin, P.; Chollacoop, N. Spray visualization of biodiesel and diesel in a high pressure chamber. Adv. Mater. Res. 2014, 931, 1043-1047.

24. Desantes, J.M.; Payri, R.; Salvador, F.J.; Gil, A. Development and validation of a theoretical model for diesel spray penetration. Fuel 2006, 85, 910-917.

25. Lee, C.S.; Park, S.W. An experimental and numerical study on fuel atomization characteristics of high-pressure diesel injection sprays. Fuel 2002, 81, 2417-2423.

26. Hiroyasu, H.; Arai, M. Fuel spray penetration and spray angle in diesel spray. Trans. JSAE 1980, $21,5-11$.

27. Dos Santos, F.; le Moyne, L. Spray atomization models in engine applications, from correlations to direct numerical simulations. Oil Gas Sci. Technol. 2011, 66, 801-822. 
28. Roisman, I.V.; Araneo, L.; Tropea, C. Effect of ambient pressure on penetration of a diesel spray. Int. J. Multiph. Flow 2007, 33, 904-920.

29. He, C.; Ge, Y.; Tan, J.; Han, X. Spray properties of alternative fuels: A comparative analysis of biodiesel and diesel. Int. J. Energy Res. 2008, 32, 1329-1338.

(C) 2015 by the authors; licensee MDPI, Basel, Switzerland. This article is an open access article distributed under the terms and conditions of the Creative Commons Attribution license (http://creativecommons.org/licenses/by/4.0/). 